\title{
Proportional assist ventilation versus pressure support ventilation for weaning from mechanical ventilation in adults: weaning success and mortality
}

\author{
Ioannis Pantazopoulos ${ }^{1}$, Georgios Mavrovounis ${ }^{1 *} \mathbb{D}$, Maria Mermiri ${ }^{2}$ and Christos Kampolis ${ }^{3}$
}

\section{To the Editor,}

We have read with great interest the timely and well written meta-analysis by Ou-Yang et al. [1]. The authors conclude that proportional assist ventilation (PAV), when used as a weaning method, improves the weaning success rate. Although we agree with the main conclusion of the authors, we would like to comment on some of the statements that were made.

Firstly, in the Materials and Methods section, the authors state that "The primary outcome was weaning success, defined as the absence of the requirement for invasive mechanical ventilation support.... Nevertheless, in the analysis of weaning success, we noted that the authors have included patients from the study by Xirouchaki et al. [2] that remained on proportional assist ventilation with load adjustable gain factors $(\mathrm{PAV}+)$ for $48 \mathrm{~h}$. According to the definition stated by Ou-Yang et al. [1], switching from a controlled mode to assist ventilation should not be considered as weaning success. Figure 1 depicts the meta-analysis of weaning success with the proposed change. PAV is still associated with a significantly higher rate of weaning success but with a risk ratio of 1.20 (95\% CI $1.07,1.34$ ) compared to 1.16 (95\% CI $1.07-1.26)$ that was reported by the authors.

Furthermore, the authors state that one of the secondary outcomes that was investigated is in-hospital mortality. However, with the exception of the study by Elganady et al. [3], the numbers used in the analysis for in-hospital mortality correspond to the numbers for ICU mortality. In order to clarify this, Fig. 2 presents the results of metaanalyses for both in-hospital mortality and ICU mortality between PAV and pressure support ventilation (PSV).

In conclusion, we fully agree with the main conclusion of the well-executed systematic review and meta-analysis by $\mathrm{Ou}$-Yang LJ et al., but we wanted to point out those inaccuracies in order to provide accurate and consistent information to the scientific community. to the material. If material is not included in the article's Creative Commons licence and your intended use is not permitted by statutory regulation or exceeds the permitted use, you will need to obtain permission directly from the copyright holder. To view a copy of this licence, visit http://creativecommons.org/licenses/by/4.0/. The Creative Commons Public Domain Dedication waiver (http://creativeco mmons.org/publicdomain/zero/1.0/) applies to the data made available in this article, unless otherwise stated in a credit line to the data. 


\begin{tabular}{|c|c|c|c|c|c|c|c|c|c|}
\hline \multirow[b]{2}{*}{ Study or Subgroup } & \multicolumn{8}{|c|}{ Successful weaning } & \\
\hline & \multicolumn{2}{|c|}{ PAV } & $\begin{array}{c}\text { PSV } \\
\text { Events }\end{array}$ & Total & \multirow{2}{*}{$\begin{array}{r}\text { Weight } \\
7.1 \%\end{array}$} & $\begin{array}{c}\text { Risk Ratio } \\
\text { M-H, Fixed, 95\% CI }\end{array}$ & \multicolumn{3}{|c|}{$\begin{array}{c}\text { Risk Ratio } \\
\text { M-H, Fixed, 95\% CI }\end{array}$} \\
\hline Bosma & 20 & 27 & 12 & 23 & & $1.42[0.90,2.23]$ & & & \\
\hline Botha & 23 & 25 & 19 & 24 & $10.7 \%$ & $1.16[0.92,1.47]$ & & $t=$ & \\
\hline Elganady & 27 & 30 & 20 & 30 & $11.0 \%$ & $1.35[1.02,1.79]$ & & $\longrightarrow$ & \\
\hline Salama & 55 & 75 & 50 & 75 & $27.6 \%$ & $1.10[0.89,1.36]$ & & $f=$ & \\
\hline Sasikumar & 12 & 13 & 7 & 10 & $4.4 \%$ & $1.32[0.85,2.04]$ & & & \\
\hline Teixeira & 42 & 48 & 38 & 46 & $21.4 \%$ & $1.06[0.89,1.26]$ & & $t=$ & \\
\hline Xirouchaki & 44 & 108 & 31 & 100 & $17.8 \%$ & $1.31[0.91,1.90]$ & & $-\infty$ & \\
\hline Total $(95 \% \mathrm{Cl})$ & & 326 & & 308 & $100.0 \%$ & $1.20[1.07,1.34]$ & & $>$ & \\
\hline Total events & 223 & & 177 & & & & & & \\
\hline $\begin{array}{l}\text { Heterogeneity: } \mathrm{Chi}^{2}= \\
\text { Test for overall effect }\end{array}$ & $\begin{array}{l}4.34, \mathrm{df} \\
Z=3.16\end{array}$ & $\begin{array}{l}=6(P \\
5(P=0\end{array}$ & $\begin{array}{l}=0.63) ; 1 \\
.002)\end{array}$ & $1^{2}=0 \%$ & & & $\begin{array}{ll}\vdash \\
0.1 & 0.2\end{array}$ & 0.5 & 10 \\
\hline
\end{tabular}

Fig. 1 Meta-analysis of weaning success. PAV proportional assisted ventilation, PSV pressure support ventilation, Cl confidence interval

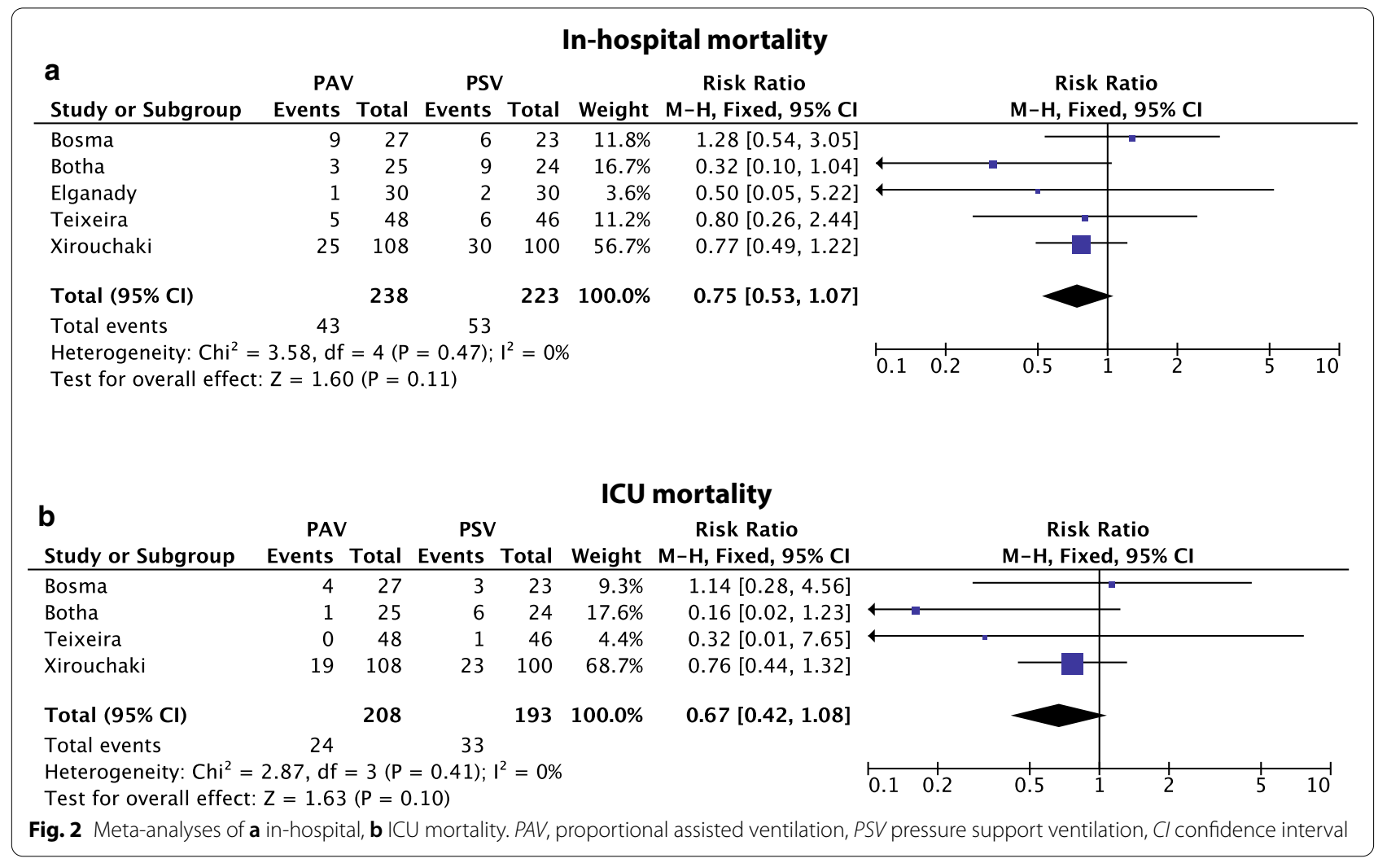

\section{Authors' response}

Liang-Jun Ou-Yang, Po-Huang Chen, Hong-Jie Jhou, Vincent Yi-Fong Su and Cho-Hao Lee

We appreciate the precise comments by Pantazopoulos et al., pointing out the details of our outcome descriptions.

According to the study by Xirouchaki et al. [2], 108 patients were included in the proportional assist ventilation (PAV) group initially, with 96 of them did not meet the "failure criteria", which meant that switching to the controlled mode was not necessary. Among them, 27 patients were extubated successfully. In the pressure support ventilation (PSV) group, 19 patients were extubated. We carefully performed the meta-analysis again using the corrected data mentioned above, which is shown in Fig. 3. The rate of weaning success was significantly greater in patients receiving PAV compared to patient undergoing PSV (fixed effect, RR 1.19 CI 1.06-1.33, $I^{2}=0 \%$, Cochran $\mathrm{Q} p$-value: 0.67$)$. We also utilized the corrected data to perform trial-sequential analysis of our major outcome, 


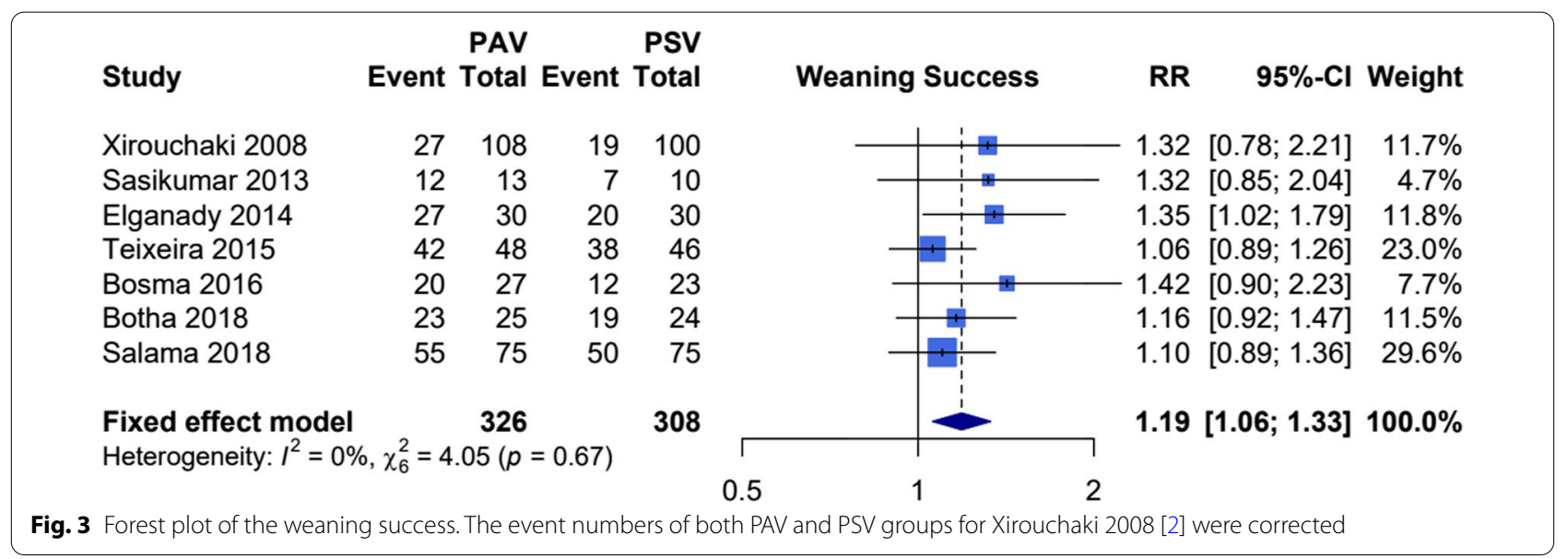

the weaning success. The TSA-adjusted RR was 1.19 (95\% CI 1.01-1.39). The main conclusion does not alter despite the data modification.

In our meta-analysis, five of seven included studies compared the mortality rate in both PAV and PSV group. The study by Elganady et al. [3] evaluated 28-day mortality, and other four studies evaluated both in-hospital and ICU mortality. We are very grateful that Pantazopoulos et al. helped clarifying our mistakes and performed metaanalyses of both ICU and in-hospital mortality. "All-cause mortality" may be a more proper term for the mixed data we presented initially.

In summary, the outcomes of weaning success, ICU mortality, and in-hospital mortality were double checked. According to the meta-analysis and TSA using the revised data, the PAV can still significantly improve the weaning success rate. Considering the mortality, "allcause mortality" may be more appropriate to described the results presented in our original manuscript. We thank Pantazopoulos et al. again for their valuable comments on our meta-analysis, helping us to provide more accurate information to the academic communities.

\section{Acknowledgements}

None.

\section{Authors' contributions}

$\mathrm{PI}$ conceived the idea and prepared the initial draft of the letter, MG performed the statistical analysis and prepared the initial draft of the letter, MM performed data acquisition and performed the statistical analysis, KC performed data acquisition and provided supervision. All authors approved the final version of the letter.

\section{Funding}

None.

\section{Availability of data and materials}

All data generated or analysed during this study are included in this published article [and its supplementary information files].

\section{Declarations}

Ethics approval and consent to participate

Not applicable.

Consent for publication

Not applicable.

\section{Competing interests}

The authors declare that they have no competing interests.

\section{Author details}

${ }^{1}$ Department of Emergency Medicine, Faculty of Medicine, School of Health Sciences, University of Thessaly, 41110 Larissa, Greece. ${ }^{2}$ Department

of Anesthesiology, Faculty of Medicine, School of Health Sciences, University of Thessaly, Larissa, Greece. ${ }^{3}$ Department of Emergency Medicine, Ippokrateio General Hospital, Athens, Greece.

Received: 30 March 2021 Accepted: 13 April 2021

Published online: 10 June 2021

\section{References}

1. Ou-Yang L-J, Chen P-H, Jhou H-J, Su VY-F, Lee C-H. Proportional assist ventilation versus pressure support ventilation for weaning from mechanical ventilation in adults: a meta-analysis and trial sequential analysis. Crit Care. 2020;24(1):556.

2. Xirouchaki N, Kondili E, Vaporidi K, Xirouchakis G, Klimathianaki M, Gavriilidis $\mathrm{G}$, et al. Proportional assist ventilation with load-adjustable gain factors in critically ill patients: comparison with pressure support. Intensive Care Med. 2008;34(11):2026-34.

3. Elganady AA, Beshey BN, Abdelaziz AAH. Proportional assist ventilation versus pressure support ventilation in the weaning of patients with acute exacerbation of chronic obstructive pulmonary disease. Egypt J Chest Dis Tubercul. 2014;63(3):643-50.

\section{Publisher's Note}

Springer Nature remains neutral with regard to jurisdictional claims in published maps and institutional affiliations. 